\title{
Plasma Adrenaline: Relations to Blood Pressure, Blood Platelet Function and Blood Lipids in Essential Hypertension
}

\author{
Sverre E. Kjeldsen', Knut Lande' ${ }^{2}$ Knut Gjesdal², Paul Leren² and Ivar K. Eide ${ }^{2}$ \\ 'Department of Internal Medicine, Division of Hypertension, The University of Michigan Medical Center, 3918 \\ Taubman Center, Ann Arbor, MI 48109-0356, USA and 'Department of Internal Medicine, Oslo University Medical \\ School, Ullevaal Hospital, Oslo, Norway \\ Key Words: adrenaline, blood pressure, catecholamines, heart rate, hypertension, lipoproteins, noradrenaline, platelet \\ function, sympathetic tone
}

\begin{abstract}
Introduction
For various reasons plasma catecholamines should be measured in arterial blood when comparing hypertensive and normotensive groups $(1,2)$. Measurements of plasma catecholamines in peripheral venous blood may conceal important hypertensive-normotensive differences (2). Plasma catecholamines seem to be subjected to a peripheral arterialvenous fractional extraction of approximately $50 \%$. Thus, arterial adrenaline represents the effective adrenaline concentration to which the tissues are exposed. Besides, plasma noradrenaline in peripheral venous blood mainly represents local release related to skeletal muscle sympathetic tone which seems unchanged in essential hypertension (3).
\end{abstract}

\section{Heart Rate and Plasma Catecholamines in Essential Hypertension}

Increased heart rate in essential hypertension may be caused by an increase of sympathetic tone, decrease of parasympa-

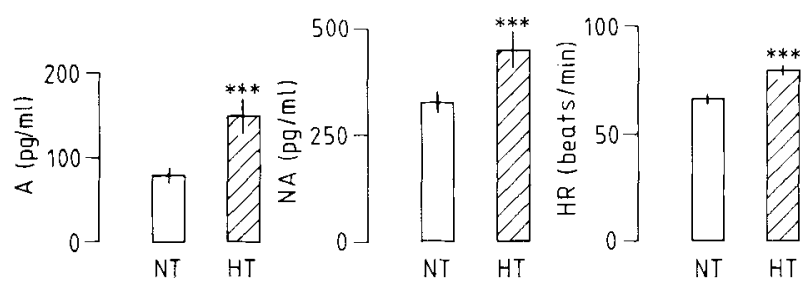

Fig. 1. Resting arterial plasma catecholamines and heart rate (means \pm SE) in 50-year-old men, normotensive (NT) controls (open bars; blood pressure (BP): $132 \pm 3 / 83 \pm 2 \mathrm{mmHg} ; \mathrm{n}=19)$ and untreated patients with sustained essential hypertension (HT: hatched bars; BP: $176 \pm 4 / 115 \pm 2 \mathrm{mmHg} ; n=20$ ). A: adrenaline; NA: noradrenaline; HR: heart rate. ${ }^{* * *}, \mathrm{p}<0.001$. Data from Kjeldsen et al. (1). thetic tone, or both (4). According to our observations (1, 2) concomitantly increased heart rate and arterial catecholamines may be encountered in essential hypertension (Fig. 1). Such correlations observed between blood pressure, heart rate and arterial catecholamine concentrations are compatible with an increase of sympathetic tone possibly combined with less parasympathetic cardiac inhibition playing a causative role in the genesis of essential hypertension. If, however, another pathophysiological mechanism than altered autonomic function was operating, cardiac frequency would have been unchanged or even depressed by activated baroreflexes.

\section{Plasma Adrenaline and Blood Platelet Function in Essential Hypertension}

In several studies we have related increased platelet function to raised sympathetic adrenergic tone in essential hypertension. A positive correlation was found between increased arterial plasma adrenaline and plasma concentration of the platelet release reaction marker beta-thromboglobulin (5). When a small, physiological dose of adrenaline was infused to essential hypertensive subjects (6), their platelet count, platelet size and plasma concentration of beta-thromboglobulin increased more than in normotensive control subjects (Fig. 2). Thus, hypertensive blood platelets seem to possess hypersensitivity to adrenaline. The explanation may be found in the lack of a rapid alpha $a_{2}$-adrenoceptor desensitizing mechanism in hypertension (7).

\section{Plasma Adrenaline and Blood Lipids}

The enzyme lipoprotein lipase is involved in the formation of high-density lipoprotein (HDL)-like particles through catebolism of triglyceride-rich very low-density lipoprotein (VLDL) particles (8). Hence, the finding of an inverse corre- 

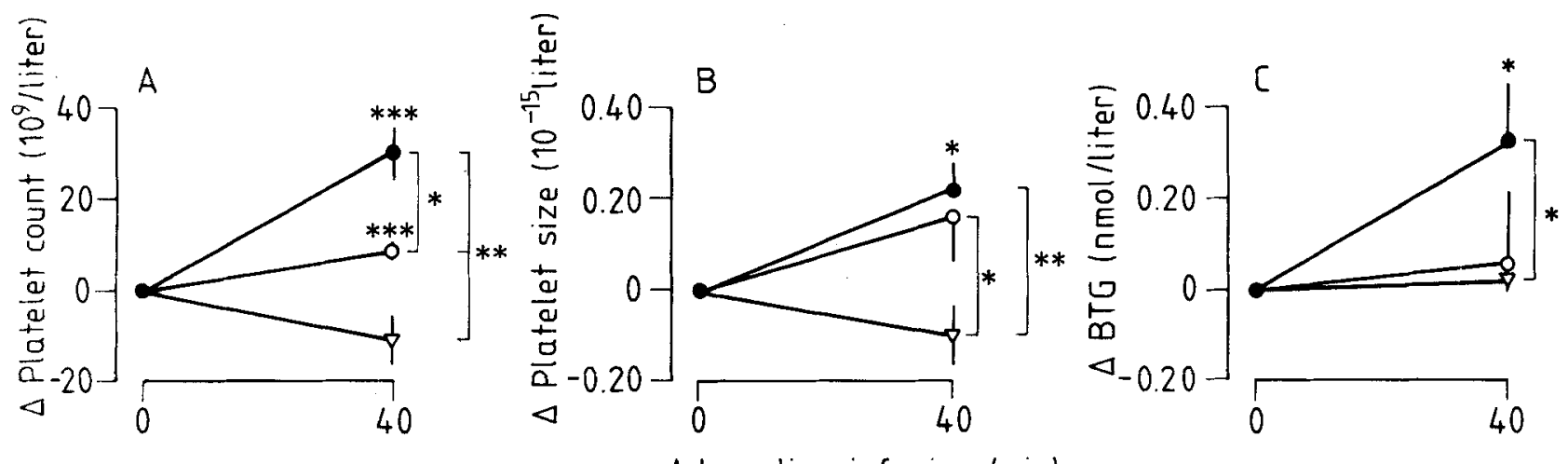

Adrenaline infusion (min)

Fig. 2. Effect of i.v. adrenaline infusion on (A) platelet count; (B) platelet size and (C) plasma concentrations of beta-thromboglobulin (BTG) in 40-year-old men with untreated mild essential hypertension $(\boldsymbol{\bullet} ; \mathrm{n}=12 ; \mathrm{BP}: 154 \pm 3 / 100 \pm 3 \mathrm{mmHg}$; means $\pm \mathrm{SE})$ and normotensive control men given adrenaline $(\mathrm{O} ; \mathrm{n}=11 ; \mathrm{BP} 124 \pm 3 / 78 \pm 2 \mathrm{mmHg})$ and sodium chloride $0.9 \%(\triangle ; \mathrm{n}=12 ; \mathrm{BP} ; 126 \pm 3 / 80 \pm 1 \mathrm{mmHg})$. Adrenaline infusion was increased by $0.01 \mu \mathrm{g} / \mathrm{kg} / \mathrm{min}$ every $10 \mathrm{~min}$ giving arterial concentrations of $4-500 \mathrm{pg} / \mathrm{ml}$ after 40 min. ${ }^{*} \mathrm{p}<0.05$; ${ }^{* *} p<0.01 ; * * * p<0.001$. Data from Lande et al. (6).

lation between HDL and triglycerides was expected (9). Catecholamines seem to inactivate lipoprotein lipase (10), possibly through effects mediated by alpha-adrenoceptors (11). Such a mechanism may explain the positive correlation between LDL + VLDL cholesterol and increased arterial adrenaline in subjects with essential hypertension (5) and also, in animals, the increased total cholesterol level due to elevation of plasma adrenaline within the pathophysiological range (12).

Both beta - -selective and the combined beta $a_{1}$ and beta $a_{2}-$ adrenoceptor blockade lower HDL and increase triglyceride concentrations $(9,11,13)$. The mechanisms by which beta-

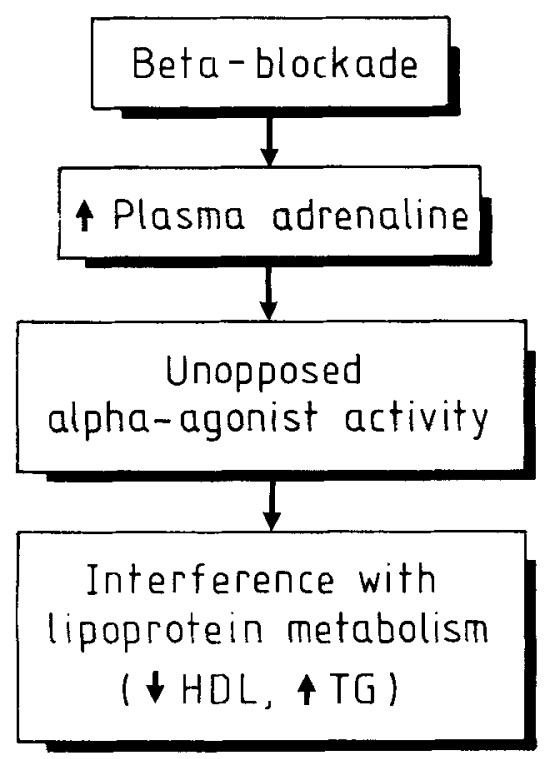

Fig. 3. Mechanisms by which plasma adrenaline may interfere with lipoprotein metabolism. HDL: high-density lipoprotein; TG: triglyceride. Initially suggested by Day et al. (9). adrenoceptor blockade induces these metabolic effects are uncertain. However, both beta ${ }_{1}$-selective and combined beta ${ }_{1}$ - and beta $a_{2}$-adrenoceptor blockade increase circulating adrenaline, especially during exercise (Gullestad et al., to be published). It has been suggested (11) that elevated plasma catecholamines during long-term beta-adrenoceptor blockade exert their inhibiting effect on lipoprotein lipase through unopposed alpha-adrenoceptor activity (Fig. 3), in harmony with the general tendency of alpha-adrenoceptor blockade to oppose the effects of beta-adrenoceptor blockade on blood lipoproteins (13).

\section{Acknowledgements}

This study was supported by grants from the Norwegian Council on Cardiovascular Diseases and Randi and Hans Arnet's Legacy, Oslo, Norway. We would like to thank Mrs. Ruth Amundsen, technician, and Mr. Ingvar Aakesson, biochemist, both Department of Internal Medicine, Ullevaal Hospital, Oslo, Norway, for expert laboratory work, and Ms. Barbara Stoner, Department of Internal Medicine, Division of Hypertension, The University of Michigan Medical Center, Ann Arbor, Michigan, U.S.A., for typewriting this manuscript.

\section{References}

1. Kjeldsen SE, Flaaten B, Eide I, Helgeland A, Leren P: Evidence of increased peripheral catecholamine release in patients with long-standing, untreated essential hypertension. Scand J Clin Lab Invest 42: 217-223 (1982).

2. Kjeldsen SE, Eide I, Aakesson I, Leren P: Increased arterial catecholamine concentrations in 50-year-old men with essential hypertension. Scand J Clin Lab Invest 43: 343-349 (1983).

3. Mörlin C, Wallin BG, Eriksson BM: Muscle sympathetic activity and plasma noradrenaline in normotensive and hypertensive man. Acta Physiol Scand 119: 117-121 (1983). 
4. Julius S, Pascual AV, London R: Role of parasympathetic inhibition in the hyperkinetic type of borderline hypertension. Circulation 44: 413-418 (1971).

5. Kjeldsen SE, Gjesdal K, Eide I, Aakesson I, Amundsen R, Foss OP, Leren P: Increased $\beta$-thromboglobulin in essential hypertension: interactions between arterial plasma adrenaline, platelet function and blood lipids. Acta Med Scand 213: 369-373 (1983).

6. Lande K, Kjeldsen SE, Os I, Westheim A, Hjermann I, Eide I, Gjesdal K: Increased platelet and vascular smooth muscle reactivity to low-dose adrenaline infusion in mild essential hypertension. J Hypertens, 6: 219-225 (1988).

7. Hollister AS, Onrot J, Lonce S, Nadeau JHJ, Robertson D. Plasma catecholamine modulation of alpha-2 adrenoceptor agonist affinity and sensitivity in normotensive and hypertensive human platelets. J Clin Invest 77: 1416-1421 (1986).

8. Patsch JR, Gotto AM, Olivecrona T, Eisenberg S: Formation of high density lipoprotein ${ }_{2}$-like particles during lipolysis of very low density lipoprotein in vitro. Proc Natl Acad Sci 75: 4519-4523 (1978).

9. Kjeldsen SE, Eide I, Leren P, Foss OP, Holme I, Eriksen IL: The effect of HDL cholesterol of oxprenolol and atenolol. Scand J Clin Lab Invest 42: 449-453 (1982).

10. Ashby P, Parkin S, Walker K, Bennett DP, Robinson DS: Hormonal control of adipose tissue lipoprotein lipase activity. INSERM Symposia 87: 149-159 (1979).

11. Day JL, Metcalfe J, Simpson CN: Adrenergic mechanisms in control of plasma lipid concentrations. $B r \operatorname{Med} J$ 284: 1145-1148 (1982).

12. Dimsdale JE, Herd A, Hartley H: Epinephrine mediated increases in plasma cholesterol. Psychosomatic Med 45: 227-232 (1983).

13. Leren P, Foss OP, Helgeland A, Hjermann I, Holme I, LundLarsen PG: Effect of propranolol and prazosin on blood lipids. The Oslo Study. Lancet ii: 4-6 (1980). 